\title{
Tolerância de maçã 'Gala' a baixas temperaturas durante o armazenamento
}

\author{
Tolerance of 'Gala' apple to low temperature during storage
}

\author{
Auri Brackmann ${ }^{\mathrm{I} *}$ Marcelo CerettaII Josuel Alfredo Vilela Pinto $^{\mathrm{I}}$ \\ Thiago Liberalesso Venturini ${ }^{I}$ Alessandro Dal Col Lúcio
}

RESUMO

O presente trabalho foi desenvolvido com o objetivo de avaliar a tolerância de maçãs 'Gala' a temperaturas baixas, em diferentes períodos, durante o armazenamento. Os tratamentos avaliados foram as temperaturas de 0 (padrão); $-0,8$ e $-1,6^{\circ} \mathrm{C}$, durante quatro meses de armazenamento refrigerado $(A R)$ e durante oito meses em atmosfera controlada (AC) a 1,0kPa de $\mathrm{O}_{2}+2,0 \mathrm{kPa}$ de $\mathrm{CO}_{2}$; e de combinação dessas temperaturas por diferentes períodos de tempo no início ou no final do armazenamento. Observando os resultados, as temperaturas de 0 e $0,8^{\circ} \mathrm{C}$ proporcionaram melhor qualidade aos frutos em relação a $-1,6^{\circ} \mathrm{C}$, em $\mathrm{AR}$. Em AC, a qualidade dos frutos foi superior em $0^{\circ} \mathrm{C}$, em comparação com as temperaturas de 0,8 e $-1,6^{\circ} \mathrm{C}$. As temperaturas de $-1,6^{\circ} \mathrm{C}$, para $o \mathrm{AR}$, e de $-0,8$ e $-1,6^{\circ} \mathrm{C}$, para $\mathrm{AC}$, quando aplicadas no início do armazenamento, foram mais prejudiciais à qualidade dos frutos do que seu uso no período final de armazenamento, provocando, principalmente, degenerescência interna, dano externo e podridões.

Palavras-chave: distúrbio fisiológico, atmosfera controlada, refrigeração.

\section{ABSTRACT}

This research was carried out to evaluate the tolerance of 'Gala' apples to low temperatures in different periods during storage. The treatments were the temperature of $0^{\circ} \mathrm{C}$ (standard); $-0.8^{\circ} \mathrm{C}$ and $-1.6^{\circ} \mathrm{C}$, during 4 months in cold storage and during 8 months in $\mathrm{CA}$ storage at $1,0 \mathrm{kPa}$ of $\mathrm{O}_{2}+$ $2,0 \mathrm{kPa}$ of $\mathrm{CO}_{2}$, and combinations of these temperatures with different times in the beginning or in the end of the storage period. Observing the results, the temperatures of $0^{\circ} \mathrm{C} e-0.8^{\circ} \mathrm{C}$ showed better quality than in $-1.6^{\circ} \mathrm{C}$ after 4 months of cold storage. AC fruit quality was higher in $0^{\circ} \mathrm{C}$ when compared with $-0.8^{\circ} \mathrm{C}$ and $-1.6^{\circ} \mathrm{C}$. The temperatures of $-1.6^{\circ} \mathrm{C}$ for cold storage and of $-0.8^{\circ} \mathrm{C}$ and $-1.6^{\circ} \mathrm{C}$ for controlled atmosphere storage, when used in the beginning of storage period were more damaging to quality than in the end of storage, causing mainly internal breakdown, injury of peel and decay.

Key words: physiological disorder, controlled atmosphere, cold storage.

\section{INTRODUÇÃO}

A temperatura é o fator mais importante do armazenamento para a manutenção da qualidade de maçãs. Tanto no Brasil, como no exterior, já se tem definida, para as principais cultivares, uma temperatura fixa de armazenamento que permite obter um longo período de conservação com qualidade. Entretanto, muitas vezes não se consegue um controle eficiente dessas temperaturas, que estão próximas do limite tolerado pelos frutos, ocorrendo oscilações consideráveis, que, se prolongadas, podem causar danos aos frutos. Tal variação de temperatura é dependente dos equipamentos de controle utilizados, que poderão ser obsoletos ou pouco confiáveis. Outro fator está relacionado à qualificação técnica dos operadores desses equipamentos, que, por falta de

IDepartamento de Fitotecnia, Centro de Ciências Rurais (CCR), Universidade Federal de Santa Maria (UFSM). Av. Roraima, n ${ }^{\circ}$ 1000, Cidade Universitária, Bairro Camobi, CP 97105-900, Santa Maria, RS, Brasil. E-mail: auribrackman@gmail.com.*Autor para correspondência.

IIMinistério da Agricultura, Pecuária e Abastecimento (MAPA), Unidade de Santa Maria, Santa Maria, RS, Brasil 
cuidado ou conhecimento, podem expor os frutos à temperatura abaixo da recomendada. Além disso, outra situação que pode ocorrer é o uso de temperaturas mais baixas no período inicial do armazenamento, que visa à rápida retirada do calor do campo, porém esse período, se prolongado, poderia danificar os frutos.

Embora a baixa temperatura de armazenamento reduza a taxa respiratória e o metabolismo, algumas reações são sensíveis e cessam completamente quando abaixo de uma temperatura crítica. Dessa forma, a exposição dos frutos à temperatura abaixo da ideal pode promover um desequilíbrio no metabolismo, levando ao colapso das células e à manifestação de distúrbios fisiológicos. Assim, BRACKMANN et al. (1996) constataram que, na temperatura de $0,5^{\circ} \mathrm{C}$, há maior incidência de rachaduras e degenerescência interna em maçãs 'Gala', em comparação com a temperatura $2,5^{\circ} \mathrm{C}$, e GHERGHI et al. (1994) afirmam que a cultivar 'Jonathan' deve ser armazenada a $3^{\circ} \mathrm{C}$ e que temperaturas mais baixas causam degenerescência da polpa.

A degenerescência interna da polpa é um dos principais distúrbios fisiológicos de maçãs causados por temperaturas abaixo do nível crítico. Conforme GRAN \& BEAUDRY (1993), esse distúrbio inicia seu desenvolvimento na parte mediana da polpa $\mathrm{e}$, frequentemente, se estende numa faixa contínua. As áreas afetadas apresentam uma coloração marrom-clara e são separadas da epiderme por uma camada de tecido sadio. Geralmente não aparecem sintomas externos, porém o fruto parece ser levemente esponjoso ao ser comprimido.

Para a maioria das cultivares de maçãs, a temperatura de armazenamento está na faixa de $-1 \mathrm{a} 00^{\circ} \mathrm{C}$ (HARDENBURG et al., 1986). Diversos trabalhos têm mostrado que a temperatura ideal de armazenamento para a 'Gala' é de $0^{\circ} \mathrm{C}$ (KUPFERMAN, 1994; SAQUET et al., 1997; BRACKMANN et al., 2001). Entretanto, não se sabe o período de tempo que essa cultivar suportaria temperaturas abaixo da ideal $\left(0^{\circ} \mathrm{C}\right)$ e nem em que período do armazenamento os frutos são mais sensíveis à baixa temperatura.

Desse modo, frente às oscilações de temperatura que podem ocorrer na câmara de armazenamento e aos impactos que a temperatura abaixo da ideal provoca na qualidade dos frutos, objetivou-se com este trabalho avaliar a tolerância da maçã 'Gala' a temperaturas de $0,-0,8$ e $-1,6^{\circ} \mathrm{C}$ durante diferentes períodos e momentos do armazenamento em AR e AC, bem como o seu efeito na qualidade dos frutos.

\section{MATERIAL E MÉTODOS}

O experimento foi desenvolvido no ano 2000, no Núcleo de Pesquisa em Pós-colheita (NPP) do Departamento de Fitotecnia da Universidade Federal de Santa Maria, com frutos da cultivar 'Gala' provenientes de um pomar comercial localizado no município de Vacaria, Rio Grande do Sul (RS). No mesmo dia da colheita, os frutos foram transportados para o NPP e, no dia seguinte, foram selecionados, eliminando-se aqueles com lesões e/ou defeitos.

Esse experimento foi subdividido em dois subexperimentos, conduzidos simultaneamente, devido ao tempo total de armazenamento, que, em armazenamento refrigerado (AR), foi de quatro meses, e em atmosfera controlada (AC) foi de oito meses. Os tratamentos avaliados estão apresentados na tabela 1 , em que foram usadas as temperaturas de $0^{\circ} \mathrm{C}$, considerada padrão; $-0,8$ e - $1,6^{\circ} \mathrm{C}$. Essas temperaturas foram utilizadas durante o período inicial ou período final, ou então durante todo o período de armazenamento, sempre completando um tempo total de quatro meses para AR e oito meses para AC. Os frutos armazenados em $\mathrm{AC}$ foram submetidos à pressão parcial de $1,0 \mathrm{kPa}$ de $\mathrm{O}_{2}+2,0 \mathrm{kPa}$ de $\mathrm{CO}_{2}$.

$\mathrm{O}$ delineamento experimental adotado foi $\mathrm{o}$ inteiramente casualizado, com quatro repetições, e a unidade experimental foi composta de 20 frutos. Foram efetuados análise da variância e teste " $F$ " e de contraste, pelo método de Scheffé, em que a comparação deu-se entre grupos de tratamentos e não entre todos os tratamentos. Foram efetuados somente dois tipos de estimativas de contrastes, que foram:

a) Entre o tratamento considerado padrão versus tratamentos com temperaturas mais baixas, ambos armazenados por quatro ou oito meses, para AR e AC, respectivamente (área hachurada, contrastes $\mathrm{X}_{1}$, Tabela 1);

b) Comparação entre grupos de tratamentos com temperaturas mais baixas no período inicial do armazenamento versus os grupos de tratamentos que tinham essas mesmas temperaturas, porém no período final (área hachurada, contrastes $\mathrm{X}_{2} \mathrm{e} \mathrm{X}_{3}$ ).

Os frutos foram armazenados em minicâmaras experimentais, com volume de $0,232 \mathrm{~m}^{3}$, acondicionadas em câmaras frigoríficas com volume de $45 \mathrm{~m}^{3}$. Após o fechamento das minicâmaras, foram estabelecidas as condições de atmosfera controlada pela diluição do $\mathrm{O}_{2}$ das minicâmaras por meio da injeção de $\mathrm{N}_{2}$ até as condições pré-estabelecidas. As pressões parciais de $\mathrm{CO}_{2}$ foram obtidas por meio da injeção desse gás no interior da minicâmaras até as condições desejadas. Nos tratamentos em AR, as minicâmaras não 
Tabela 1 - Relação dos tratamentos para a maçã 'Gala' em armazenamento refrigerado e em atmosfera controlada e definição dos contrastes com respectivos coeficientes.

\begin{tabular}{|c|c|c|c|}
\hline \multicolumn{4}{|c|}{ Atmosfera controlada } \\
\hline & - & ---Contrastes e coeficientes---- & 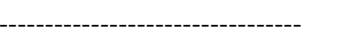 \\
\hline Temperatura e tempo de exposição & $\begin{array}{c}\mathrm{X} 1=\text { Comparação de } 0^{\circ} \mathrm{C} \\
\text { com }-0,8^{\circ} \mathrm{C} .\end{array}$ & $\begin{array}{c}\mathrm{X} 2=\mathrm{Comparação} \mathrm{de}- \\
0,8^{\circ} \mathrm{C} \text { no início com }-0,8^{\circ} \mathrm{C} \\
\text { no final. }\end{array}$ & $\begin{array}{l}\mathrm{X} 3 \text { = Comparação de }-1,6^{\circ} \mathrm{C} \\
\text { no início com }-1,6^{\circ} \mathrm{C} \text { no final. }\end{array}$ \\
\hline $0^{\circ} \mathrm{C}$ por 8 meses (padrão) & 1 & 0 & 0 \\
\hline$-0,8^{\circ} \mathrm{C}$ por 8 meses & -1 & 0 & 0 \\
\hline$-1,6^{\circ}$ por 8 meses & - & 0 & 0 \\
\hline$-0,8^{\circ} \mathrm{C}$ por 2 meses $^{*}+0^{\circ} \mathrm{C}$ por 6 meses $^{* *}$ & 0 & 1 & 0 \\
\hline$-0,8^{\circ} \mathrm{C}$ por 4 meses $+0^{\circ} \mathrm{C}$ por 4 meses & 0 & 1 & 0 \\
\hline $0^{\circ} \mathrm{C}$ por 6 meses $+\left(-0,8^{\circ} \mathrm{C}\right)$ por 2 meses & 0 & -1 & 0 \\
\hline $0^{\circ} \mathrm{C}$ por 4 meses $+\left(-0,8^{\circ} \mathrm{C}\right)$ por 4 meses & 0 & -1 & 0 \\
\hline$-1,6^{\circ} \mathrm{C}$ por $1 / 2$ mês $+0^{\circ} \mathrm{C}$ por $71 / 2$ meses & 0 & 0 & 1 \\
\hline$-1,6^{\circ} \mathrm{C}$ por 1 mês $+0^{\circ} \mathrm{C}$ por 7 meses & 0 & 0 & 1 \\
\hline$-1,6^{\circ} \mathrm{C}$ por 2 meses $+0^{\circ} \mathrm{C}$ por 6 meses & 0 & 0 & 1 \\
\hline$-1,6^{\circ} \mathrm{C}$ por 4 meses $+0^{\circ} \mathrm{C}$ por 4 meses & 0 & 0 & - \\
\hline $0^{\circ} \mathrm{C}$ por $71 / 2$ meses $+\left(-1,6^{\circ} \mathrm{C}\right)$ por $1 / 2$ mês & 0 & 0 & -1 \\
\hline $0^{\circ} \mathrm{C}$ por 7 meses $+\left(-1,6^{\circ} \mathrm{C}\right)$ por 1 mês & 0 & 0 & -1 \\
\hline $0^{\circ} \mathrm{C}$ por 6 meses $+\left(-1,6^{\circ} \mathrm{C}\right)$ por 2 meses & 0 & 0 & -1 \\
\hline $0^{\circ} \mathrm{C}$ por 4 meses $+\left(-1,6^{\circ} \mathrm{C}\right)$ por 4 meses & 0 & 0 & - \\
\hline Temperatura e tempo de exposição & $\begin{array}{c}\mathrm{X} 1 \text { = Comparação de } 0^{\circ} \mathrm{C} \\
\text { com }-0,8^{\circ} \mathrm{C} \mathrm{e}-1,6^{\circ} \mathrm{C} .\end{array}$ & $\begin{array}{c}\mathrm{X} 2=\text { Comparação de }-0,8^{\circ} \mathrm{C} \\
\text { no início, com }-0,8^{\circ} \mathrm{C} \text { no } \\
\text { final. }\end{array}$ & $\begin{array}{l}\mathrm{X} 3 \text { = Comparação de }-1,6^{\circ} \mathrm{C} \\
\text { no início, com }-1,6^{\circ} \mathrm{C} \text { no } \\
\text { final. }\end{array}$ \\
\hline $0^{\circ} \mathrm{C}$ por 4 meses (padrão) & 2 & 0 & 0 \\
\hline$-0,8^{\circ} \mathrm{C}$ por 4 meses & -1 & 0 & 0 \\
\hline$-1,6^{\circ} \mathrm{C}$ por 4 meses & -1 & 0 & 0 \\
\hline$-0,8^{\circ} \mathrm{C}$ por 1 mês $^{*}+0^{\circ} \mathrm{C}$ por 3 meses $^{* *}$ & 0 & 1 & 0 \\
\hline$-0,8^{\circ} \mathrm{C}$ por 2 meses $+0^{\circ} \mathrm{C}$ por 2 meses & 0 & 1 & 0 \\
\hline $0^{\circ} \mathrm{C}$ por 3 meses $+\left(-0,8^{\circ} \mathrm{C}\right)$ por 1 mês & 0 & -1 & 0 \\
\hline $0^{\circ} \mathrm{C}$ por 2 meses $+\left(-0,8^{\circ} \mathrm{C}\right)$ por 2 meses & 0 & -1 & 0 \\
\hline$-1,6^{\circ} \mathrm{C}$ por $1 / 2$ mês $+0^{\circ} \mathrm{C}$ por $31 / 2$ meses & 0 & 0 & 1 \\
\hline$-1,6^{\circ} \mathrm{C}$ por 1 mês $+0^{\circ} \mathrm{C}$ por 3 meses & 0 & 0 & 1 \\
\hline$-1,6^{\circ} \mathrm{C}$ por 2 meses $+0^{\circ} \mathrm{C}$ por 2 meses & 0 & 0 & 1 \\
\hline $0^{\circ} \mathrm{C}$ por $31 / 2$ meses $+\left(-1,6^{\circ} \mathrm{C}\right)$ por $1 / 2$ mês & 0 & 0 & -1 \\
\hline $0^{\circ} \mathrm{C}$ por 3 meses $+\left(-1,6^{\circ} \mathrm{C}\right)$ por 1 mês & 0 & 0 & -1 \\
\hline $0^{\circ} \mathrm{C}$ por 2 meses $+\left(-1,6^{\circ} \mathrm{C}\right)$ por 2 meses & 0 & 0 & -1 \\
\hline
\end{tabular}

*No início do armazenamento. **No final do armazenamento.

foram fechadas hermeticamente como nos tratamentos em AC, para evitar a formação de uma atmosfera modificada. O monitoramento da temperatura foi feito diariamente com termômetros de mercúrio de alta precisão.

Devido à respiração dos frutos, as pressões parciais de $\mathrm{O}_{2} \mathrm{e} \mathrm{CO}_{2}$ no interior das minicâmaras de $\mathrm{AC}$ modificaram-se constantemente. Para a manutenção das pressões parciais pré-estabelecidas, as minicâmaras foram conectadas a um equipamento de análise e correção de gases automatizado, marca Kronenberger Systemtechnik, que monitorava a concentração dos gases diariamente e várias vezes ao dia. Para aumentar a pressão parcial de $\mathrm{O}_{2}$ nas minicâmaras, o equipamento injetava ar atmosférico. $\mathrm{O}$ excesso de $\mathrm{CO}_{2}$ era removido por meio do acionamento automático de um absorvedor de $\mathrm{CO}_{2}$, à base de uma solução de hidróxido de potássio $( \pm 40 \%)$.

As análises da qualidade dos frutos foram realizadas após armazenamento de quatro e oito meses, 
respectivamente, para $\mathrm{AR}$ e $\mathrm{AC}$, mais sete dias de exposição a $20^{\circ} \mathrm{C}$, para simular o período de comercialização desses frutos. Foram analisados os seguintes parâmetros: firmeza da polpa, teor de sólidos solúveis, incidência de podridões e degenerescência interna, conforme metodologia citada por BRACKMANN \& SAQUET (1995), e dano na epiderme, que foi caracterizado por manchas na epiderme, de cor marrom e aspecto úmido, mole e geralmente abrangendo grande área do fruto, sendo os dados expressos em percentual de frutos afetados. A produção de etileno, avaliada no final do experimento e com frutos a $20^{\circ} \mathrm{C}$, foi determinada conforme metodologia descrita por VIZZOTTO et al. (2002) e expressa em $\mu \mathrm{L} \mathrm{kg}^{-1} \mathrm{~h}^{-1}$. O parâmetro incidência de podridão foi avaliado na saída da câmara e após sete dias de exposição a $20^{\circ} \mathrm{C}$, já o dano na epiderme foi avaliado somente na saída da câmara, e todos os de mais parâmetros foram avaliados após sete dias de exposição a $20^{\circ} \mathrm{C}$.

\section{RESULTADOS E DISCUSSÃO}

As estimativas de contrastes para as variáveis firmeza da polpa e SST (Tabela 2) mostram efeito não significativo entre o tratamento-padrão, $0^{\circ} \mathrm{C}$, em relação ao tratamento com $-0,8$ e $-1,6^{\circ} \mathrm{C}$ (contrastes $\mathrm{X}_{1}$, Tabela 1). Nos outros contrastes $\left(\mathrm{X}_{2} \mathrm{e} \mathrm{X}_{3}\right)$, também não houve efeito significativo para essas variáveis, independente da temperatura usada no início ou no final do armazenamento.

As estimativas de contraste $X_{1}$ para degenerescência interna mostraram efeito significativo entre o tratamento considerado padrão, $0^{\circ} \mathrm{C}$, em relação aos tratamentos com armazenamento a $-0,8$ e $-1,6^{\circ} \mathrm{C}$ (Tabela 2), e no tratamento-padrão não houve degenerescência interna (Tabela 3 e 4). Já na temperatura de $-0,8^{\circ} \mathrm{C} \mathrm{em} \mathrm{AC}$, o percentual foi elevado, chegando a 69,5\% (Tabela 4). Os frutos em AC, no tratamento com $-1,6^{\circ} \mathrm{C}$ por oito meses ininterruptos $\mathrm{e}$ tratamento de $-1,6^{\circ} \mathrm{C}$ por quatro meses $+0^{\circ} \mathrm{C}$ por quatro meses (Tabela 4), apresentaram 100 e $95 \%$ de degenerescência interna, respectivamente, o que impossibilitou a avaliação da maioria das outras variáveis. Conforme LYONS (1973), após um período prolongado de exposição ao frio, ocorre perda da integridade da membrana, vazamento de solutos, desorganização da estrutura celular e manifestação de sintomas típicos de tecidos danificados. Fica evidente então o cuidado que se deve ter na manutenção da temperatura ideal durante $\mathrm{o}$ armazenamento.

Nos contrastes $X_{2}$ e $X_{3}$, em que foram comparados os grupos de tratamentos com as temperaturas mais baixas no período inicial com os grupos de tratamentos que apresentaram essas mesmas temperaturas no período final do armazenamento, houve interação entre os contrastes, tanto em AC, quanto em AR. Constatando-se, então, maior incidência de degenerescência interna nos frutos submetidos a temperaturas mais baixas no período inicial do armazenamento. WATKINS et al. (1997) relacionam esse distúrbio ao estádio de maturação do fruto, que, no início do armazenamento, ainda não é completo, sendo portanto o fruto mais sensível ao frio.

$\mathrm{O}$ dano na epiderme só ocorreu nos frutos armazenados em AC (Tabela 4). Nestes, o contraste $X_{1}$ (Tabela 2) mostrou que os tratamentos-padrão tiveram

Tabela 2 - Estimativas de contrastes para as variáveis, avaliadas na abertura da câmara ( 0 dias $)$ ou após sete dias, para a maçã 'Gala', em atmosfera controlada durante oito meses e em armazenamento refrigerado durante quatro meses, sob diferentes temperaturas e diferentes períodos de exposição.

\begin{tabular}{|c|c|c|c|c|c|c|c|}
\hline \multirow{2}{*}{ Contrastes $^{1}$} & \multirow{2}{*}{ Firmeza $(\mathrm{N})$} & \multirow{2}{*}{$\operatorname{SST}\left({ }^{\circ}\right.$ Brix $)$} & \multirow{2}{*}{$\begin{array}{c}\text { Degener. } \\
\text { interna }(\%)\end{array}$} & \multirow{2}{*}{$\begin{array}{c}{ }^{2} \text { Dano na } \\
\text { epiderme }(\%)\end{array}$} & \multicolumn{2}{|c|}{-------Podridão(\%)------- } & \multirow{2}{*}{$\begin{array}{c}\text { Etileno } \\
\left(\mu \mathrm{Lg}^{-1} \mathrm{~h}^{-1}\right)\end{array}$} \\
\hline & & & & & 0 dias & 7 dias & \\
\hline $\mathrm{X} 1$ & $0,10^{\mathrm{ns}}$ & $0,03^{\mathrm{ns}}$ & $-6,67 *$ & $-10,00^{*}$ & & $-18,81^{*}$ & 0,07 \\
\hline $\mathrm{X} 2$ & $-0,10^{\text {ns }}$ & $-0,26^{\text {ns }}$ & $96,34^{*}$ & $10,02 *$ & $9,97 *$ & $40,54^{*}$ & 0,12 \\
\hline $\mathrm{X} 3$ & $-1,80^{\mathrm{ns}}$ & $0,00^{\mathrm{ns}}$ & $21,65^{*}$ & $78,37 *$ & $21,65^{*}$ & $68,75^{*}$ & 0,68 \\
\hline \multirow{2}{*}{ Contrastes } & \multirow{2}{*}{ Firmeza $(\mathrm{N})$} & \multirow{2}{*}{\multicolumn{2}{|c|}{ SST $\left({ }^{\circ}\right.$ Brix $)$}} & \multirow{2}{*}{ Degener. Interna (\%) } & \multicolumn{2}{|c|}{-------Podridão (\%)------- } & \multirow{2}{*}{$\begin{array}{c}\text { Etileno } \\
\left(\mu \mathrm{L} \mathrm{kg}^{-1} \mathrm{~h}^{-1}\right)\end{array}$} \\
\hline & & & & & 0 dias & 7 dias & \\
\hline $\mathrm{X} 1$ & $-1,30^{\mathrm{ns}}$ & 0,1 & & $-14,99 *$ & $0^{\text {ns }}$ & $-1,67 *$ & $113,20^{*}$ \\
\hline $\mathrm{X} 2$ & $-0,10^{\mathrm{ns}}$ & -0, & & $1,67^{*}$ & $1,66^{*}$ & $0,25^{\mathrm{ns}}$ & $-16,30 *$ \\
\hline $\mathrm{X} 3$ & $-1,90^{\mathrm{ns}}$ & 1,1 & & $1,67 *$ & $1,67^{*}$ & $1,67 *$ & $-36,90 *$ \\
\hline
\end{tabular}

\footnotetext{
${ }^{1}=$ Conforme definição na tabela $1 . *$ = significativo pelo teste de Scheffé, com nível de $5 \%$ de probabilidade. ${ }^{2}=$ Análise na abertura das câmaras. ${ }^{\mathrm{ns}}=$ não significativo
} 
Tabela 3 - Qualidade da maçã 'Gala' após quatro meses de armazenamento refrigerado, sob diferentes temperaturas e diferentes períodos de exposição, mais sete dias a $20^{\circ} \mathrm{C}$.

\begin{tabular}{|c|c|c|c|c|c|c|}
\hline \multirow{2}{*}{ Temperatura e tempo de exposição } & \multirow{2}{*}{$\begin{array}{c}\text { Firmeza da } \\
\text { polpa }(\mathrm{N})\end{array}$} & \multirow{2}{*}{$\begin{array}{c}\text { SST } \\
\left({ }^{\circ} \text { Brix }\right)\end{array}$} & \multirow{2}{*}{$\begin{array}{c}\text { Deg } \\
\text { interna }(\%)\end{array}$} & \multicolumn{2}{|c|}{-------Podridão (\%)------- } & \multirow{2}{*}{$\begin{array}{c}{ }^{*} \mathrm{C}_{2} \mathrm{H}_{4} \\
\left(\mu \mathrm{Lg}^{-1} \mathrm{~h}^{-1}\right)\end{array}$} \\
\hline & & & & 0 dias & 7 dias & \\
\hline $0^{\circ} \mathrm{C}$ por 4 meses & 52,8 & 11,6 & 0 & 0 & 0 & 62,3 \\
\hline$-0,8^{\circ} \mathrm{C}$ por 4 meses & 60,6 & 11,3 & 0 & 0 & 0 & 10,2 \\
\hline$-1,6^{\circ} \mathrm{C}$ por 4 meses & 57,7 & 11,7 & 14,99 & 0 & 1,7 & 1,2 \\
\hline$-0,8^{\circ} \mathrm{C}$ por 1 mês $+0^{\circ} \mathrm{C}$ por 3 meses & 52,8 & 11,2 & 1,67 & 0 & 0 & 52,8 \\
\hline$-0,8^{\circ} \mathrm{C}$ por 2 meses $+0^{\circ} \mathrm{C}$ por 2 meses & 55,7 & 11,1 & 0 & 3,3 & 1,9 & 38,8 \\
\hline $0^{\circ} \mathrm{C}$ por 3 meses $+\left(-0,8^{\circ} \mathrm{C}\right)$ por 1 mês & 52,8 & 11,1 & 0 & 1,7 & 1,7 & 70,3 \\
\hline $0^{\circ} \mathrm{C}$ por 2 meses $+\left(-0,8^{\circ} \mathrm{C}\right)$ por 2 meses & 56,7 & 11,5 & 0 & 0 & 0 & 37,6 \\
\hline$-1,6^{\circ} \mathrm{C}$ por $1 / 2$ mês $+0^{\circ} \mathrm{C}$ por $3 \frac{1}{2}$ meses & 55,7 & 11,7 & 0 & 0 & 0 & 59,1 \\
\hline$-1,6^{\circ} \mathrm{C}$ por 1 mês $+0^{\circ} \mathrm{C}$ por 3 meses & 56,7 & 11,5 & 0 & 0 & 1,7 & 44,1 \\
\hline$-1,6^{\circ} \mathrm{C}$ por 2 meses $+0^{\circ} \mathrm{C}$ por 2 meses & 56,7 & 11,7 & 4,99 & 1,7 & 3,3 & 25,6 \\
\hline $0^{\circ} \mathrm{C}$ por $3 \frac{1 / 2}{2}$ meses $+\left(-1,6^{\circ} \mathrm{C}\right)$ por $1 / 2$ mês & 48,9 & 11,2 & 1,67 & 0 & 0 & 70,9 \\
\hline $0^{\circ} \mathrm{C}$ por 3 meses $+\left(-1,6^{\circ} \mathrm{C}\right)$ por 1 mês & 49,8 & 11,3 & 0 & 0 & 0 & 67,5 \\
\hline $0^{\circ} \mathrm{C}$ por 2 meses $+\left(-1,6^{\circ} \mathrm{C}\right)$ por 2 meses & 51,8 & 11,3 & 1,67 & 0 & 3,3 & 27,3 \\
\hline
\end{tabular}

* Média de sete dias, a $20^{\circ} \mathrm{C}$.

menor dano na epiderme, enquanto que os frutos armazenados por oito meses ininterruptos a $-1,6^{\circ} \mathrm{C}$ e aqueles mantidos nessa mesma temperatura por quatro meses iniciais tiveram 100 e $95 \%$, respectivamente, de dano na epiderme (Tabela 4). Assim, pode-se concluir que a associação entre AC e baixa temperatura potencializa a ocorrência de dano na epiderme. Desse modo, controle rigoroso da temperatura é imprescindível quando se deseja armazenar maçãs 'Gala' em AC.

Maior ocorrência de dano na epiderme foi constatada nos frutos submetidos a temperaturas mais baixas nos períodos iniciais do armazenamento, em relação aos frutos submetidos às mesmas temperaturas,

Tabela 4 - Qualidade da maçã 'Gala', armazenada em diferentes temperaturas e diferentes períodos de exposição, após oito meses de atmosfera controlada mais sete dias a $20^{\circ} \mathrm{C}$.

\begin{tabular}{|c|c|c|c|c|c|c|c|}
\hline \multirow{2}{*}{ Temperatura e tempo de exposição } & \multirow{2}{*}{$\begin{array}{l}\text { Firmeza } \\
(\mathrm{N})\end{array}$} & \multirow{2}{*}{$\begin{array}{c}\text { SST } \\
\left({ }^{\circ} \text { Brix }\right)\end{array}$} & \multirow{2}{*}{$\begin{array}{c}\text { Deg } \\
\text { interna } \\
(\%)\end{array}$} & \multirow{2}{*}{$\begin{array}{c}{ }^{1} \text { Dano na } \\
\text { epiderme } \\
(\%)\end{array}$} & \multicolumn{2}{|c|}{---Podridão (\%)--- } & \multirow{2}{*}{$\begin{array}{c}* \mathrm{C}_{2} \mathrm{H}_{4} \\
\left(\mu \mathrm{kg}^{-1} \mathrm{~h}^{-1}\right)\end{array}$} \\
\hline & & & & & 0 dias & 7 dias & \\
\hline $0^{\circ} \mathrm{C}$ por 8 meses & 56,7 & 12,2 & 0 & 0 & 3,3 & 13,8 & 0,42 \\
\hline$-0,8^{\circ} \mathrm{C}$ por 8 meses & 57,7 & 12,2 & 69,5 & 10,0 & 10,0 & 32,6 & 0,49 \\
\hline$-1,6^{\circ}$ por 8 meses & - & - & 100 & 100,0 & - & - & - \\
\hline$-0,8^{\circ} \mathrm{C}$ por 2 meses $+0^{\circ} \mathrm{C}$ por 6 meses & 56,7 & 11,9 & 45,7 & 3,35 & 6,7 & 18,1 & 0,55 \\
\hline$-0,8^{\circ} \mathrm{C}$ por 4 meses $+0^{\circ} \mathrm{C}$ por 4 meses & 54,7 & 11,5 & 59,3 & 6,67 & 5,0 & 33,2 & 0,45 \\
\hline $0^{\circ} \mathrm{C}$ por 6 meses $+\left(-0,8^{\circ} \mathrm{C}\right)$ por 2 meses & 55,7 & 12,0 & 3,4 & 0 & 0,0 & 5,0 & 0,56 \\
\hline $0^{\circ} \mathrm{C}$ por 4 meses $+\left(-0,8^{\circ} \mathrm{C}\right)$ por 4 meses & 56,7 & 11,7 & 5,1 & 0 & 1,7 & 5,8 & 0,32 \\
\hline$-1,6^{\circ} \mathrm{C}$ por $1 / 2$ mês $+0^{\circ} \mathrm{C}$ por $71 / 2$ meses & 55,7 & 11,9 & 31,9 & 0 & 5,0 & 29,8 & 0,63 \\
\hline$-1,6^{\circ} \mathrm{C}$ por 1 mês $+0^{\circ} \mathrm{C}$ por 7 meses & 52,8 & 11,8 & 54,4 & 20,0 & 8,3 & 38,0 & 0,62 \\
\hline$-1,6^{\circ} \mathrm{C}$ por 2 meses $+0^{\circ} \mathrm{C}$ por 6 meses & 44,9 & 11,5 & 72,2 & 63,4 & 10,0 & 43,7 & 0,56 \\
\hline$-1,6^{\circ} \mathrm{C}$ por 4 meses $+0^{\circ} \mathrm{C}$ por 4 meses & - & - & 95 & 95 & - & - & - \\
\hline $0^{\circ} \mathrm{C}$ por $71 / 2$ meses $+\left(-1,6^{\circ} \mathrm{C}\right)$ por $1 / 2$ mês & 55,7 & 12,0 & 33,6 & 0 & 0,0 & 14,1 & 0,42 \\
\hline $0^{\circ} \mathrm{C}$ por 7 meses $+\left(-1,6^{\circ} \mathrm{C}\right)$ por 1 mês & 57,7 & 11,5 & 33,8 & 0 & 1,7 & 18,7 & 0,38 \\
\hline $0^{\circ} \mathrm{C}$ por 6 meses $+\left(-1,6^{\circ} \mathrm{C}\right)$ por 2 meses & 57,7 & 11,7 & 34,7 & 5,03 & 0,0 & 10,0 & 0,33 \\
\hline $0^{\circ} \mathrm{C}$ por 4 meses $+\left(-1,6^{\circ} \mathrm{C}\right)$ por 4 meses & 51,8 & 11,6 & 60,0 & 16,7 & 0,0 & 26,6 & 0,30 \\
\hline
\end{tabular}

${ }^{1}=$ Análise na abertura das câmaras. ${ }^{*}=$ Médias de dois dias a $20^{\circ} \mathrm{C}$. 
porém no período final (contrastes $\mathrm{X}_{2} \mathrm{e} \mathrm{X}_{3}$ ). Esse dano caracterizou-se por manchas de cor marrom de aspecto úmido e mole, apresentando, nos casos mais severos, uma depressão na epiderme, provavelmente, ocasionado pela perda de líquido celular devido ao congelamento interno. O estresse por frio, que culmina com a formação de cristais de gelo no tecido dos frutos, foi mais intenso no início do armazenamento, pois nesse período os frutos contêm mais água e, consequentemente, temperatura de congelamento maior que no final do armazenamento.

Quando são observados os dados da ocorrência de degenerescência interna, pode-se relacionar que o dano na epiderme foi uma extensão da degenerescência interna, pois onde o primeiro foi mais severo o segundo também o foi, porém num percentual menor. Pode-se então afirmar que o dano na epiderme foi causado pelo frio. LITTLE \& BARRAND (1989) afirmam que o resfriamento gradativo diminui a suscetibilidade à baixa temperatura, já que o estresse pelo frio parece ser mais crítico no início do armazenamento.

Para a incidência de podridões, no contraste $\mathrm{X}_{1}$ em AR, não foi verificada incidência de podridões nos tratamentos mantidos nas temperaturas de $0^{\circ} \mathrm{e}$ $0,8^{\circ} \mathrm{C}$, já a $-1,6^{\circ} \mathrm{C}$ a incidência de podridão foi de $1,7 \%$ (Tabela 3). Em AC, a incidência foi menor somente no tratamento-padrão a $0^{\circ} \mathrm{C}$. Esses resultados foram constatados na avaliação efetuada logo após a abertura das câmaras e também após exposição dos frutos por sete dias a $20^{\circ} \mathrm{C}$. A temperatura de $-1,6^{\circ} \mathrm{C}$, durante quatro meses em $\mathrm{AR}$, e as temperaturas de $-0,8 \mathrm{e}-1,6^{\circ} \mathrm{C}$, durante oito meses em AC, usadas de forma ininterrupta, agravaram a incidência de podridões, fato que deve estar relacionado à maior ocorrência de dano na epiderme, no caso dos tratamentos em AC, facilitando assim $\mathrm{o}$ ataque de patógenos.

Nos contrastes $\mathrm{X}_{2}$ e $\mathrm{X}_{3}$, foi constatada maior incidência de podridão nos frutos submetidos a temperaturas mais baixas no início do armazenamento. Ficou evidente então que temperaturas mais baixas no início são mais prejudiciais do que no final do período de armazenamento. Quando essas mesmas temperaturas foram aplicadas por igual período, porém no final do armazenamento, a incidência de podridões foi menor, mesmo após a exposição dos frutos por sete dias a $20^{\circ} \mathrm{C}$. BRACKMANN et al. (2000), trabalhando com a maçã 'Fuji', constataram que temperatura mais elevada $\left(2,5^{\circ} \mathrm{C}\right)$ por 40 dias, no início do armazenamento, reduz a ocorrência de podridões.

Para a variável produção de etileno, somente houve significância estatística nos frutos armazenados em AR (Tabela 2). $\mathrm{O}$ tratamento $0^{\circ} \mathrm{C}$ por quatro meses, considerado padrão, estimulou uma maior produção de etileno do que $-0,8$ e $-1,6^{\circ} \mathrm{C}$ (contraste $X_{1}$, Tabela 2 ). Assim, parece que as temperaturas mais baixas causaram alguma inibição de enzimas que, posteriormente, reduziu a produção mais acentuada de etileno. LARRIGAUDIERE et al. (1997) mostraram que o decréscimo da síntese de etileno e a redução da temperatura estão associados à diminuição na atividade da ACC-oxidase e sugeriram que esse efeito pode ser, primeiramente, relacionado à termodinâmica da enzima e, posteriormente, à alteração nas propriedades das membranas celulares induzidas pelo frio.

\section{CONCLUSÃO}

Maçãs 'Gala' podem ser mantidas em armazenamento refrigerado, em temperatura igual ou superior a $-0,8^{\circ} \mathrm{C}$, durante quatro meses. Em $\mathrm{AC}$, temperaturas de $-0,8^{\circ} \mathrm{C}$ ou inferiores provocam maior degenerescência interna causada pelo frio, quando usadas no início do armazenamento, principalmente quando o tempo de exposição for igual ou superior a dois meses. Temperaturas de $-1,6^{\circ} \mathrm{C}$ para $\mathrm{AR}$ e de $0,8^{\circ} \mathrm{C}$ ou inferiores para $\mathrm{AC}$, quando aplicadas no início do armazenamento, tendem a provocar mais podridões. A maçã 'Gala' tolera, sem grandes perdas, a temperatura de $-1,6^{\circ} \mathrm{C}$ nos dois meses finais do período de quatro meses de armazenamento. Já em AC a temperatura de $0,8^{\circ} \mathrm{C}$ pode ser usada no final do armazenamento por até quatro meses, sem comprometer a qualidade dos frutos.

\section{REFERÊNCIAS}

BRACKMANN, A. et al. Armazenamento de maçãs 'Royal Gala' sob diferentes temperaturas e pressões parciais de oxigênio e gás carbônico. Revista Brasileira de Fruticultura, Jaboticabal, v.23, n.3, p.532-536, 2001. Disponível em: <http:/ / w w w. s c i e 1 o.br/s c i e 1 o.ph p ? p i d = S $0100-$ $29452001000300016 \&$ script=sci_arttext $>$. Acesso em: 29 jul. 2010. doi: 10.1590/S0100-29452001000300016.

BRACKMANN, A. et al. Concentrações de $\mathrm{O}_{2}$ e $\mathrm{CO}_{2}$ na qualidade de maçãs (Malus domestica Borck) cv. Gala, armazenadas a $0,5^{\circ} \mathrm{C}$ e $2,5^{\circ} \mathrm{C}$. Revista Brasileira de Agrociência, Pelotas, v.2, p.51-56, 1996. Disponível em: <http://www.scielo.br/scielo.php?pid=S0103$90162000000200001 \&$ script=sci_arttext>. Acesso em: 29 jul. 2010. doi: 10.1590/S0103-90162000000200001.

BRACKMANN, A. et al. Conservação da maçã 'Fuji' sob diferentes temperaturas, umidade relativa e momentos de instalação da atmosfera de armazenamento. Ciência Rural, Santa Maria, v.30, n.1, p.81-84, 2000.

BRACKMANN, A.; SAQUET, A.A. Armazenamento de maçã cv. Gala em atmosfera controlada. Revista Brasileira de Agrociência. Pelotas, v.1, n.2, p.55-60, 1995. 
GHERGHI, A. et al. The influence of low oxygen concentration during storage on metabolical processes in apples. Acta Horticulturae, Wageningen, n.368, p.608-613, 1994.

GRAN, C.D.; BEAUDRY R.M. Determination of the low oxygen limit for several commercial apple cultivars by respiratory quotient breakpoint. Postharvest Biology and Technology, Amsterdam, v.3, p.259-267, 1993.

HARDENBURG, R.E. et al. The comercial storage of fruits, vegetables and florist and nursery stocks. Washington: U.S.D.A., 1986. 136p. (Agriculture Handbook, 66).

KUPFERMAN, E.M. Maturity and storage of Gala, Fuji and Braeburn apples. Tree fruit Postharvest Journal, Washington, v.5, n.3, p.10-15, 1994.

LARRIGAUDIERE, C. et al. Cultivar differences in the influence of a short period of cold storage on ethylene biosynthesis in apples. Postharvest Biology Technology, Amsterdam, v.10, p.21-27, 1997.

LITTLE,C.R., BARRAND, L. The effect of preharvest, postharvest and storage conditions on some fruits disorders. In: INTERATIONAL CONTROLLED ATMOSPHERE RESEARCH
CONFERENCE, 5., 1989, Washington. Proceedings... Washington: Washington State University, 1989. V.1, 515p. p.185192.

LYONS, J.M. Chilling injury in plant. Annual Review of Plant Physiology, Palo Alto, n.24, p.495-496, 1973.

SAQUET, A.A. et al. Armazenamento de maçã 'Gala' sob diferentes temperaturas e concentrações de oxigênio e gás carbônico. Ciência Rural, Santa Maria, v.27, n.3, p.399-405, 1997. Disponível em: <http://www.scielo.br/scielo.php?script=sci_arttext\&pid=S0103$84781997000300006 \& \operatorname{lng}=\mathrm{pt} \& \mathrm{nrm}=\mathrm{iso} \& \operatorname{tlng}=\mathrm{pt}>$. Acesso em: 18 ago. 2010. doi: 10.1590/S0103-84781997000300006.

VIZZOTTO, M. et al. Aplicação de cálcio em pré-colheita na conservação de pêssego [Prunus persica (L.) BATSCH.] cv. Chiripá. Revista Brasileira de Agrociência. Pelotas, v.8, n.1, p.31-35, 2002.

WATKINS, C.B., et al. A comparison of two carbon dioxiderelated injuries of apple fruit. In: INTERNATIONAL CONTROLLED ATMOSPHERE RESEARCH CONFERENCE, 7., 1997, California. Proceedings... Davis: University of California, 1997. V.2, p.119-124. 